\title{
Assessment of sleep quality of patients with panic disorder and generalized anxiety disorder during remission: a case-control study
}

\author{
YUNUS HACIMUSALAR ${ }^{1}$ \\ https://orcid.org/0000-0002-1777-2707
}

OZGUL KARAASLAN11

Received: 02/15/2019 - Accepted: 09/04/2019

DOl: 10.1590/0101-60830000000224

1 Bozok University Faculty of Medicine, Department of Psychiatry, Yozgat, Turkey.

\begin{abstract}
Background: Sleep disorders are common in psychiatric diseases. Panic disorder (PD) and generalized anxiety disorder (GAD) are two major anxiety disorders that are associated with sleep disorders. Objective: We hypothesized that poor sleep quality continues in PD and GAD during remission. Therefore, in this study we aimed to compare the sleep quality of patients with PD and GAD to that of healthy controls. Methods: The study included patients with PD ( $\mathrm{n}=42$ ) and GAD $(n=40)$ who had been in remission for at least 3 months and healthy control volunteers $(n=45)$. The patients were administered the Pittsburgh Sleep Quality Index (PSQI), Beck Anxiety Inventory (BAI), and Beck Depression Inventory (BDI). Results: The total PSQI scores of the GAD group were significantly increased in comparison to those of the PD $(\mathrm{p}=0.009)$ and control $(\mathrm{p}<0.001)$ groups. The rate of poor sleep quality in GAD during remission $(77.5 \%)$ was greater than that of the PD (47.6\%) and control $(51.1 \%)$ groups $(\mathrm{p}=0.011)$. Discussion: GAD is a chronic and recurrent disease. In this study, it was found that the deterioration in sleep quality of patients with GAD may continue during remission. In the follow-up and treatment of patients, it is appropriate to question about sleep symptoms and to plan interventions according to these symptoms.
\end{abstract}

Hacimusalar Y, Karaaslan O / Arch Clin Psychiatry. 2020;47(1):19-24

Keywords: Anxiety disorders, sleep quality, sleep disturbance, remission, psychiatric diseases.

\section{Introduction}

Among the anxiety disorders, panic disorder (PD) and generalized anxiety disorder (GAD) are two diseases for which patients frequently visit the clinics. The overall prevalence of anxiety disorders is estimated to be $28.8 \%$. The estimated prevalence of PD and GAD have been reported as $4.7 \%$ and $5.7 \%$, respectively ${ }^{1}$. In some studies, GAD and specific phobias are the two most common anxiety disorders ${ }^{2}$. Anxiety disorders were the sixth leading cause of disability in countries of both high and low-middle socioeconomic status. The global burden of disease approach uses the disability-adjusted life year (DALY), and globally, anxiety disorders accounted for 390 DALYs per 100,000 persons ${ }^{3}$.

In $\mathrm{PD}$ and GAD, anxiety may give rise to physical signs and cognitive symptoms such as attention and concentration impairment and sleep disruption. The symptoms and signs of anxiety and sleep disorders frequently overlap. The sleep disorder may be a preliminary indication of anxiety, as well as a risk factor for developing an anxiety disorder ${ }^{4}$. In recent years there has been a shift towards assessing the overall impact of illness on the aspects of quality of life (QoL). Determining the effects of diseases on the quality of life and applying treatments for them has become more important. Sleep disorders and poor sleep quality adversely affect QoL ${ }^{5,6}$. The sleep disorders are quite prevalent and accompany various psychiatric diseases 7,8 . Poor physical health adversely impacts mental health and quality of life ${ }^{9-11}$.

Sleep disturbance is commonly observed in individuals with anxiety disorders ${ }^{12}$. Compared to healthy controls, those with PD exhibit increased sleep onset latency, decreased sleep efficiency, decreased total sleep time, and many altered components of sleep $4,8,12,13$. A prevalence of $77 \%$ for restless and disturbed sleep and $68 \%$ for difficulties in falling asleep has been reported in patients with $\mathrm{PD}^{8}$. Individuals with GAD exhibit decreased total sleep time, increased sleep onset latency, and variations in non-rapid eye movement (NREM) sleep ${ }^{12}$. Insomnia is recognized as a serious and significant health problem in patients with $\mathrm{GAD}^{14}$. More consistent findings on sleep disturbance in GAD have been reported, and sleep disturbance is included in the GAD diagnostic criteria ${ }^{15}$. The signs and symptoms of a sleep disorder are frequently experienced when the anxiety of PD or GAD is intense ${ }^{11}$. Characteristic polysomnographic findings are present in both diseases ${ }^{8}$. Hoge et al. hypothesized that amongst individuals with $\mathrm{PD}$, higher anxiety sensitivity would be associated with sleep disruption, particularly in the form of increased sleep latency ${ }^{16}$. Higher anxiety sensitivity involves increases in attention and fearfulness about anxiety itself, and its associated physical sensations, which in turn may cause excessive arousal. Similar mechanisms may also be a cause of sleep disturbance in GAD. A day-long episode of anxiety in GAD may lead to stimulation that further causes sleep disruption. Despite all this information, the cause of sleep disorder in both PD and GAD is not known.

The period of remission in psychiatric diseases is defined as a notable reduction in signs and symptoms of the disease, or a nearly total resolution. Considering the recurring characteristics of PD and GAD, some signs and symptoms may persist in the remission period. There are many studies which have assessed the quality of sleep during the period when PD and GAD are uncontrolled. However, to the best of our knowledge, there is no study that assesses the quality of sleep in PD and GAD during remission and compares them to healthy controls. As is the case with many psychiatric diseases, the residual symptoms present in the period of improvement affect the ability of the patients to fully resume their pre-disease status and functionality. Improvement in residual symptoms, other than the main symptoms of anxiety, may significantly contribute to the feeling of wellness and functionality of the individuals. This study aimed to assess the quality of sleep of patients with PD and GAD during remission and to compare the assessment with that of healthy controls. In this study, our hypothesis was that (1) sleep quality is poorer in PD and GAD patients than in healthy controls; and (2) because GAD is more chronic, its sleep quality deterioration would be higher than in PD. 


\section{Methods}

This was a cross-sectional, case-control study. The study included patients with the diagnosis of PD and GAD according to the Diagnostic and Statistical Manual of Mental Disorders (DSM-5) diagnostic criteria ${ }^{1}$. They had presented to the psychiatry clinic of the Faculty of Medicine Hospital of Yozgat Bozok University and were followed up in the same clinic by two specialized physicians (YH, OK). Included in the study were patients aged 15-65 years, with no additional psychiatric disease, who had been in remission from PD or GAD for no less than 3 months, who were cognitively able to complete the test (Ÿdid not have difficulty in understanding the self-reported questionnaires), and who scored 9 or lower on the BDI and 7 or lower on the BAI. A clinical examination was performed, and patients with a BAI score of 7 or less at the time of the study and within the last 3 months according to hospital records were determined to be in remission. Regarding their treatments, only patients in whom selective serotonin reuptake inhibitors (SSRIs) or serotonin and norepinephrine reuptake inhibitors (SNRIs) had been prescribed were included. The control group was comprised of medical personnel employed in the same hospital and patients' relatives who were free of any physical or psychiatric ailment or known sleep disorder. For each participant, depression levels were evaluated by means of the Beck Depression Inventory (BDI), anxiety levels by means of the Beck Anxiety Inventory (BAI), and quality of sleep by means of the Pittsburgh Sleep Quality Index (PSQI). Those with chronic physical diseases, those with physical or psychiatric diseases that may cause sleep disorder, users of benzodiazepines and/ or stimulants, those with an alcohol abuse disorder, and pregnant persons were excluded. A total of 167 persons were included ( 42 with PD, 40 with GAD, and 45 healthy controls) (Figure 1).

The participants were informed about the study, and written informed consent was obtained from all participants before their entry. The study was approved by the local Ethics Committee of Yozgat Bozok University, with a protocol number of 2017-KAEK-189_2018.05.16_05, and it was performed under the ethical principles of the Declaration of Helsinki for medical research involving human subjects.

\section{Assessment tools}

\section{Data collection form}

This form was prepared by the researchers and contains information such as age, gender, education, smoking status, and height and weight of the participants.

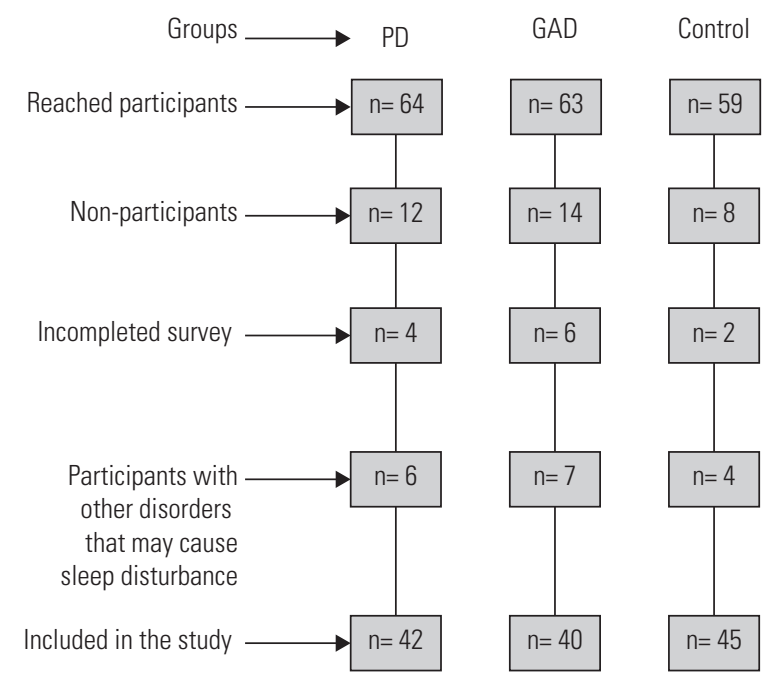

PD: panic disorder; GAD: generalized anxiety disorder

Figure 1. Flow chart of participants.

\section{Pittsburgh Sleep Quality Index (PSOI)}

The PSQI was developed by Buysse et al. ${ }^{17}$, and the Turkish validity and reliability study was conducted by Ağargün et al. ${ }^{18}$. The PSQI is a 19-item self-report scale that assesses sleep quality and disturbance over the past month. It consists of 24 questions, of which 19 involve self-assessment and 5 are answered by his or her sleep partner. The 18 questions scored in the scale consist of 7 components: subjective sleep quality, sleep latency, sleep duration, habitual sleep efficiency, sleep disturbance, use of sleep medications, and daytime dysfunction. Each component is rated from 0 to 3 points. The total score is the sum of the 7 subscales' scores. The total PSQI score ranges between 0 and 21 points. A high total PSQI score indicates poor sleep quality and severe sleep disturbance. A total PSQI score of over 5 points indicates clinically poor sleep quality.

\section{Beck Depression Inventory (BDI)}

The BDI was developed by Beck et al. ${ }^{19}$ to evaluate the physical, emotional, cognitive, and motivational symptoms seen in depression. The BDI is a scale consisting of 21 self-evaluation sentences, and each symptom category has four options. Each item is scored between 0 and 3 points, and the total score ranges from 0 to 63 points. In terms of the severity of depressive symptoms, 0 to 9 points indicates minimal symptoms. The Turkish validity and reliability study was performed by Hisli et al. ${ }^{20}$.

\section{Beck Anxiety Inventory (BAI)}

The BAI was developed by Beck et al. ${ }^{21}$ to assess the extent of an individual's anxiety symptoms. Based on self-reporting, the BAI consists of 21 items, and each item is scored between 0 and 3 points. The total score ranges from 0 to 63 points. The total score obtained from the scale indicates the severity of the individual's anxiety. The Turkish validity and reliability study was carried out by Ulusoy et al. ${ }^{22}$.

\section{Statistical analysis}

Statistical analysis was performed using the SPSS 22.0 (Statistical Package for Social Sciences, IBM Inc., Chicago, IL, USA) package program. The descriptive statistics for the data were calculated, and the Kolmogorov-Smirnov methods were applied for testing the normality distribution. The chi-square test was used for comparison of groups with respect to the categorical variables. ANOVA and the post hoc Tukey test were applied to the 3-group comparison of the data which exhibited normal distribution. The Kruskal-Wallis $\mathrm{H}$ test was used for group comparisons of non-parametric variables, and omnibus effects were explored using the Mann-Whitney $U$ test to determine which pairs of groups differed. $p$ significance was determined by dividing the significance value by the number of groups. The Bonferroni correction for multiple comparisons was used $(0.05 / 3=0.016)$. The Pearson's correlation test was used for the normally distributed data, and the Spearman's correlation test was used for data not showing a normal distribution. A regression model was established for the variables showing significant correlation, and diagnostic tests of this model were carried out. A p value of less than 0.05 was considered statistically significant. After the evaluation of previous study results, a power analysis was performed. The alpha and beta errors were stated, respectively, as 0.05 and 0.20 . The minimum number of patients needed to obtain $80 \%$ power was calculated as 34 for each group.

\section{Results}

The average age in the PD group was $44.38 \pm 13.58$ years; in the GAD group it was $47.28 \pm 10.76$ years, and in the control group it was $41.51 \pm 10.46$ years. No significant differences appeared in terms of age, gender, and smoking habits between the groups ( $\mathrm{p}>0.05)$. The body mass indexes (BMIs) of the GAD and PD groups were significantly higher compared to that of the control group 
$(\mathrm{p}<0.001)$. The duration of disease for the PD group was significantly higher than that of the GAD group $(p<0.001)$ (Table 1$)$. There was no statistically significant difference between the PD and GAD groups in terms of the medications used by the participants $(\mathrm{p}=$ 0.258 ) (Table 2).

Although the BDI and BAI scores of the patients in the PD and GAD groups remained within normal limits, they are significantly higher with reference to the control group $(\mathrm{p}<0.001)$. The difference among the three groups in terms of total PSQI scores was statistically significant $(p<0.001)$. Pairwise comparisons conducted in order to determine the source of the difference revealed statistically higher significance for the total PSQI scores of the GAD group compared to the PD and control groups ( $\mathrm{p}=0.009 ; \mathrm{p}<0.001$, respectively). When the sleep quality was assessed as poor for those having a total PSQI score higher than 5, the sleep quality of $77.5 \%(n=31)$ of the patients with GAD, $47.6 \%(n=20)$ of the patients with PD, and $51.1 \%$ of the control group patients $(n=23)$ was poor, and the difference was statistically significant $(\mathrm{p}=0.011)$. After pairwise comparisons, the proportion of GAD patients having poor sleep was significantly higher compared to the PD and control groups $(p=0.005 ; p=0.012$, respectively). The difference between the $\mathrm{PD}$ and control groups was not statistically significant ( $\mathrm{p}>0.05$ ) (Table 3 ). When a post hoc power analysis was applied with alpha 0.05 , the power of the study was found to be 0.9885 .

Table 1. Evaluation of demographic features by groups

\begin{tabular}{|c|c|c|c|c|c|}
\hline & & \multirow[b]{2}{*}{$P D(n=42)$} & \multicolumn{2}{|c|}{ Groups } & \multirow{2}{*}{$\begin{array}{c}\text { Test Value } \\
p\end{array}$} \\
\hline & & & $\operatorname{GAD}(n=40)$ & Controls $(n=45)$ & \\
\hline \multirow[t]{2}{*}{ Age } & Mean \pm SD & $44.38 \pm 13.58$ & $47.28 \pm 10.76$ & $41.51 \pm 10.46$ & F: 2.584 \\
\hline & Min-Max & $22-65$ & $23-65$ & $24-63$ & $0.080^{\mathrm{a}}$ \\
\hline BMI & Mean \pm SD & $29.26 \pm 5.54 d$ & $30.13 \pm 4.67 d$ & $26.02 \pm 5.15$ & $\mathrm{~F}: 8.544^{* *}<0.001 \mathrm{a}$ \\
\hline Smoking & Mean \pm SD (number/day) & $16.43 \pm 11.63$ & $12.44 \pm 7.58$ & $13.21 \pm 8.55$ & $F: 0.5920 .559 a$ \\
\hline \multirow[t]{2}{*}{$\begin{array}{l}\text { Duration of disease } \\
\text { (months) }\end{array}$} & $\begin{array}{l}\text { Mean } \pm \text { SD } \\
\text { Min-Max (Median) }\end{array}$ & $\begin{array}{c}67.29 \pm 8.61 \\
5-240(48)^{\mathrm{e}}\end{array}$ & $\begin{array}{c}47.58 \pm 8.48 \\
12-240(22)\end{array}$ & -- & $\begin{array}{l}\text { Z: }-2.321 \\
{ }^{*} 0.020^{b}\end{array}$ \\
\hline & & $n(\%)$ & $n(\%)$ & $\mathrm{n}(\%)$ & \\
\hline \multirow[t]{2}{*}{ Gender } & Female & $24(57.1)$ & $26(65.0)$ & $26(57.8)$ & $\chi^{2}: 0.650$ \\
\hline & Male & $18(42.9)$ & $14(35.0)$ & $19(42.2)$ & $0.723^{c}$ \\
\hline Smoking & $\begin{array}{l}\text { Smokers } \\
\text { Non-smokers }\end{array}$ & $\begin{array}{l}14(33.3) \\
28(66.7)\end{array}$ & $\begin{array}{c}9(22.5) \\
31(77.5)\end{array}$ & $\begin{array}{l}14(31.1) \\
31(68.9)\end{array}$ & $\begin{array}{c}\chi^{2}: 1.297 \\
0.523^{c}\end{array}$ \\
\hline
\end{tabular}

${ }^{*} p<0.05$. ** $p<0.01$. a ANOVA. ${ }^{\mathrm{b}}$ Mann-Whitney U test. c Pearson Chi-Square test. ${ }^{\mathrm{A}}$ Significantly higher than in the control group; ${ }^{\mathrm{e}}$ Significantly higher than in the GAD group. PD: panic disorder; GAD: generalized anxiety disorder; BMI: body mass index.

Table 2. Medications used by patients

\begin{tabular}{|c|c|c|c|c|}
\hline & & & & \\
\hline & $\mathrm{PD}(\mathrm{n}=42)$ & $\operatorname{GAD}(n=40)$ & $\chi^{2}$ & $p$ \\
\hline SSRls & $78.6 \%(n=33)$ & $67.5 \%(n=27)$ & 1.279 & 0.258 \\
\hline Escitalopram & 16 & 13 & & \\
\hline Sertraline & 7 & 5 & & \\
\hline Paroxetine & 6 & 4 & & \\
\hline Fluoxetine & 3 & 1 & & \\
\hline Citalopram & 2 & 2 & & \\
\hline Fluvoxamine & - & 1 & & \\
\hline SNRIs & $21.4 \%(n=9)$ & $32.5 \%(n=13)$ & & \\
\hline Duloxetine & 4 & 9 & & \\
\hline Venlafaxine & 5 & 4 & & \\
\hline
\end{tabular}

$\chi^{2}$ : Chi-square value; PD: panic disorder; GAD: generalized anxiety disorder; SSRIs: selective serotonin reuptake inhibitors; SNRIs: serotonin and norepinephrine reuptake inhibitors.

Table 3. Evaluation of scores of Beck Depression Scale, Beck Anxiety Scale, and Pittsburgh Sleep Quality by groups

\begin{tabular}{|c|c|c|c|c|}
\hline & \multicolumn{3}{|c|}{ Groups } & \multirow{2}{*}{$\frac{\text { Test Value }}{p}$} \\
\hline & $P D(n=42)$ & $\operatorname{GAD}(n=40)$ & Control $(n=45)$ & \\
\hline \multirow{3}{*}{$\begin{array}{l}\text { BAl } \\
\text { Min-Max (Median) } \\
\text { Mean } \pm \text { SD }\end{array}$} & & & & \\
\hline & $5-7(6)^{b}$ & $4-7(5)^{b}$ & $2-5(4)$ & $\chi^{2}: 84.562$ \\
\hline & $5.86 \pm 0.75$ & $5.58 \pm 0.74$ & $3.56 \pm 0.72$ & ${ }^{* *}<0.001^{a}$ \\
\hline \multirow{3}{*}{$\begin{array}{l}\text { BDI } \\
\text { Min-Max (Median) } \\
\text { Mean } \pm \text { SD }\end{array}$} & & & & \\
\hline & $4-6(5)^{b}$ & $3-6(4)^{b}$ & $2-4(3)$ & $\chi^{2:}: 84.677$ \\
\hline & $4.86 \pm 0.75$ & $4.58 \pm 0.55$ & $2.60 \pm 0.65$ & ${ }^{* *}<0.001^{a}$ \\
\hline \multirow{3}{*}{$\begin{array}{l}\text { PSOI } \\
\text { Min-Max (Median) } \\
\text { Mean } \pm \text { SD }\end{array}$} & & & & \\
\hline & $0-12(5)$ & $0-17(9)^{c}$ & $0-15(6)$ & $\chi 2: 15.591$ \\
\hline & $6.52 \pm 3.74$ & $9.0 \pm 4.09$ & $5.64 \pm 3.21$ & ${ }^{* *}<0.001^{a}$ \\
\hline Sleep Quality & $\mathrm{n}(\%)$ & $\mathrm{n}(\%)$ & $\mathrm{n}(\%)$ & \\
\hline Good & $22(52.4)$ & $9(22.5)$ & $22(48.9)$ & $\chi^{2}: 8.991$ \\
\hline Poor & $20(47.6)$ & $31(77.5)^{c}$ & $23(51.1)$ & ${ }^{*} 0.011 \mathrm{~d}$ \\
\hline
\end{tabular}

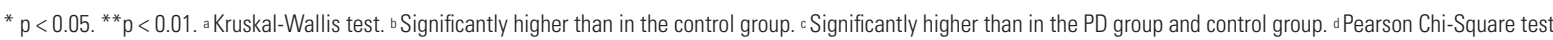
BAI: Beck Anxiety Scale; BDI: Beck Depression Scale; PSQl: Pittsburgh Sleep Quality Index; PD: panic disorder; GAD: generalized anxiety disorder. 
Analysis of the sub-components of the PSQI demonstrated a significant difference in terms of subjective sleep quality $(p=0.008)$, sleep latency $(p<0.001)$, sleep duration $(p<0.001)$, habitual sleep efficiency $(p=0.027)$, use of sleep medications $(p=0.014)$, time spent in bed $(p=0.049)$, and sleep duration $(p<0.001)$ (Table 4). When pairwise comparisons were conducted to find out the source of differences, the subjective sleep quality $(Z:-2.793 ; p=0.005)$, sleep duration ( $Z$ : $-4.002 ; \mathrm{p}<0.001)$, and habitual sleep efficiency (Z: $-2.589 ; p=0.01)$ scores of patients with GAD were significantly higher compared to those of the PD group. The scores for subjective sleep quality $(Z:-2.508 ; p=0.012)$, sleep latency $(Z:-3.762 ; p<0.001)$, and use of sleep medications $(\mathrm{Z}:-1.255 ; \mathrm{p}=0.005)$ were significantly higher in GAD patients than in controls. The sleep latency $(\mathrm{Z}$ : -3.450; $p=0.001)$, sleep duration $(Z:-2.997 ; p=0.003)$, and use of sleep medications $(\mathrm{Z}: 2.651 ; \mathrm{p}=0.008)$ of the patients with PD were significantly higher than in the control group.

In all participants evaluated together, there were positive correlations between the total PSQI scores and BMI ( $\mathrm{r}$ : 0.247; $\mathrm{p}=0.005)$, the number of cigarettes smoked daily $(\mathrm{r}: 0.422 ; \mathrm{p}=0.009)$, BAI score ( $\mathrm{r}: 0.201 ; \mathrm{p}=0.023)$, and BDI score $(\mathrm{r}: 0.204 ; \mathrm{p}=0.021)$ (Table 5). When correlation analysis was performed in each group, there were positive correlations between the total PSQI scores and BMI ( $\mathrm{r}: 0.314 ; \mathrm{p}=0.035)$ and the number of cigarettes smoked daily ( $r: 0.799 ; p=0.001$ ) only in the control group. In multiple regression analysis, the effect of daily cigarette smoking on the total PSQI level was $66.9 \%$ in healthy control patients $(\mathrm{F}[1,13]=27.264 ; \mathrm{p}<$ $0.001)$. A negative correlation existed between the total PSQI scores and duration of disease in the patient group ( $\mathrm{r}:-0.350 ; \mathrm{p}=0.001$ ). When correlation analysis was performed in each patient group, the correlation between the total PSQI scores and the duration of disease was not significant $(\mathrm{p}>0.05)$.

In multi-linear regression analysis, the evaluation of daily number of cigarettes, BMI, BAI score, and BDI score on the total PSQI scores revealed a statistically significant effect for daily number of cigarettes (Beta: $0.425 ; \mathrm{t}: 2.731 ; \mathrm{p}=0.010$ ).

Table 4. Evaluation of scores of Pittsburgh Sleep Quality Index sub-components between groups

\begin{tabular}{|c|c|c|c|c|}
\hline & \multicolumn{3}{|c|}{ Groups } & \multirow{2}{*}{$\begin{array}{c}\text { Test Value } \\
p^{a}\end{array}$} \\
\hline & $P D(n=42)$ & $\mathrm{GAD}(n=40)$ & Control $(n=45)$ & \\
\hline \begin{tabular}{|l} 
Subjective Sleep Quality \\
Min-Max (Median)
\end{tabular} & $0-3(1)$ & $0-3(2) b, c$ & $0-3(1)$ & $\begin{array}{l}\chi^{2}: 9.708 \\
0.008^{* *}\end{array}$ \\
\hline \begin{tabular}{|l|} 
Sleep Latency \\
Min-Max (Median) \\
\end{tabular} & $0-3(2)^{b}$ & $0-3(3)^{b}$ & $0-3(2)$ & $\begin{array}{l}\chi^{2:}: 18.610 \\
<0.001^{* *}\end{array}$ \\
\hline \begin{tabular}{|l|} 
Sleep Duration \\
Min-Max (Median)
\end{tabular} & $0-3(0)^{b}$ & $0-3(1) c$ & $0-3(1)$ & $\begin{array}{l}\chi^{2}: 18.618 \\
<0.001^{* *}\end{array}$ \\
\hline Habitual Sleep Efficiency & & & & $\chi^{2}: 7.201$ \\
\hline Min-Max (Median) & $0-2(0)$ & $0-3(1)^{c}$ & $0-3(0)$ & $0.027^{*}$ \\
\hline Sleep Disturbances & & & & $\chi^{2}: 2.325$ \\
\hline Min-Max (Median) & $0-2(1)$ & $0-3(1)$ & $0-2(1)$ & 0.313 \\
\hline Use of Sleep Medication & & & & $\chi^{2}: 8.527$ \\
\hline Min-Max (Median) & $0-3(0)^{\mathrm{b}}$ & $0-3(0)^{b}$ & $0-2(0)$ & $0.014^{*}$ \\
\hline Daytime Dysfunction & & & & $\chi^{2}: 5.534$ \\
\hline Min-Max (Median) & $0-3(1)$ & $0-3(1)$ & $0-3(1)$ & 0.063 \\
\hline \multicolumn{5}{|l|}{ Duration in Bed } \\
\hline Min-Max (Median) & $4-12(9)^{b}$ & $4-11(7.75)$ & $5.5-11(7.5)$ & $\chi^{2}: 6.045$ \\
\hline Avg. \pm SD & $8.31 \pm 0.25$ & $7.73 \pm 0.23$ & $7.72 \pm 0.16$ & $0.049^{*}$ \\
\hline \multicolumn{5}{|l|}{ Sleep Duration (hours) } \\
\hline Min-Max (Median) & $4.5-8(8)^{b, d}$ & $4.5-8(6.5)$ & $4.5-8(6.5)$ & $\chi^{2:}: 18.618$ \\
\hline Avg. \pm SD & $7.28 \pm 0.15$ & $6.25 \pm 0.17$ & $6.67 \pm 0.14$ & $<0.001^{* *}$ \\
\hline \multicolumn{5}{|c|}{$\begin{array}{l}\text { Sleep Percentage (sleep duration/ } \\
\text { duration in bed) }\end{array}$} \\
\hline Min-Max (Median) & $66.7-99(88.9)$ & $50-99(81.2)$ & $40.9-99(86.6)$ & $\chi^{2}: 3.387$ \\
\hline Avg. \pm SD & $87.65 \pm 1.40$ & $81.85 \pm 2.16$ & $86.28 \pm 1.63$ & 0.184 \\
\hline
\end{tabular}

${ }^{*} p<0.05$. ${ }^{* *} p<0.01$. a Kruskal-Wallis Test. b Significantly higher than in the control group. c Significantly higher than in the PD group. ${ }^{d}$ Significantly higher than in the GAD group. PD: panic disorder; GAD: generalized anxiety disorder.

Table 5. Review of correlation among Pittsburgh Sleep Quality Index, Beck Anxiety Scale, Beck Depression Scale, body mass index, daily cigarette consumption and duration of disease

\begin{tabular}{|l|c|c|}
\hline \multirow{2}{*}{ All Groups } & \multicolumn{2}{|c|}{ PSOI } \\
\cline { 2 - 3 } & \multicolumn{2}{c|}{$p$} \\
\hline BAl & & $0.023^{*}$ \\
\hline BDI & 0.201 & $0.005^{* *}$ \\
\hline BMl & 0.204 & $0.005^{* *}$ \\
\hline Daily cigarette consumption & 0.247 & $0.009^{* *}$ \\
\hline PD and GAD group & 0.422 & \\
\hline Duration of disease & & $0.001^{* *}$ \\
\hline
\end{tabular}

$r=$ Spearman's correlation coefficient. ${ }^{*} p<0.05 .{ }^{* *} p<0.01$. PSQI: Pittsburgh Sleep Quality Index; BAI: Beck Anxiety Scale; BDI: Beck Depression Scale; BMI: body mass index; PD: panic disorder; GAD: generalized anxiety disorder. 


\section{Discussion}

In this study, even though the depression and anxiety levels of the patients with $P D$ and GAD remained within normal limits, they were higher than in the control group. The sleep quality of the patients with $\mathrm{GAD}$ proved poorer in comparison to the $\mathrm{PD}$ and control groups. The sleep quality of the PD and GAD groups was poorer compared to the control group with respect to many sub-components of the PSQI. A collective evaluation of all groups suggests that smoking, increased age, and increases in BMI adversely affect sleep quality. Those with lesser duration of disease also have poorer sleep quality.

Anxiety and fear result in an increase in cortical and peripheral stimulation. Anxiety affects sleep, influencing the hypothalamicpituitary-adrenal axis and various other systems ${ }^{23}$. Stimulation also occurs in the case of any disorder that adversely affects starting and sustaining sleep. In general, a mutual interaction exists between anxiety and sleep disorder. The existence of either boosts the effect of the other ${ }^{24,25}$.

Chronic anxiety and strain comprise the basic features of GAD. GAD is associated with difficulty in starting and sustaining sleep ${ }^{4,15}$. Sleep disorder is more highly associated with GAD than with $\mathrm{PD}^{4}$. Extreme anxiety or worried expectation, the basic features of GAD play a significant role in the emergence and persistence of sleep disorders ${ }^{26}$. Certain studies have found that the prevalence of sleep disorders in patients with GAD is $50 \%$ to $85 \%$, and such disorders are observed in various stages of sleep ${ }^{8,14,27}$. It is further known that if GAD symptoms are more severe, the prevalence of insomnia is higher ${ }^{28}$. The main finding of this study is that the sleep quality of patients with GAD in remission is lower compared to the individuals in the PD and control groups. Furthermore, subjective sleep quality, sleep duration, and habitual sleep efficiency in GAD patients was lower than in the PD group. In addition, subjective sleep quality, sleep latency, and daytime dysfunction were worse in GAD patients compared to the controls. The results of our study indicate that the adverse effects of GAD on sleep may persist despite the improvement in signs and symptoms of anxiety during the period of remission. This fact may be interpreted in a manner where the chronic and recurring feature of GAD and signs of sleep disorder survive in spite of a decline in signs of anxiety or meliorate in a longer term as compared to the signs of anxiety. In the study of Ramsawh et al., the strongest relationship between sleep disorder and anxiety was discovered in the GAD group ${ }^{11}$. The sleep disorder in patients with GAD may be observed in the form of residual signs, as is the case with numerous chronic psychiatric diseases. In our study, we determined a proportion of GAD patients with poor sleep quality (77.5\%), and this percentage was just as high as it was during the peak attacks of the disease. This demonstrates that the sleep quality of patients with GAD does not improve even if the symptoms of anxiety are in remission.

Although certain studies have concluded that sleep disorder is more common in patients with PD than in healthy controls, there are other studies in which this is not addressed ${ }^{4,8}$. The panic attacks experienced during sleep may lead to insomnia by instilling fear in the individuals. One of the factors affecting the sleep disorder in PD is the presence of depression. Although the total PSQI scores of the patients with PD were similar to those of the control group, the sub-components, namely sleep latency, sleep duration, use of sleep medications, and duration in bed, were higher than in the control group. This result shows that sleep quality in patients with PD is poor in certain respects. The patients in our study did not have any panic attacks, since they were in remission. Moreover, any patients with past and current depression had been excluded.

The medications used in the treatment of anxiety disorders may also impact sleep quality. However, the patients with PD and GAD in our study exhibited similar features in terms of the medications that they used.

Smoking is considered one of the significant factors having an impact on sleep quality. It is common knowledge that smoking has adverse effects on sleep for different reasons. The number of cigarettes smoked daily is the most important factor that harms sleep quality29,30.
In our study, with all participants evaluated together, there was a positive correlation between total PSQI scores and the number of cigarettes smoked daily. However, when correlation analysis was performed in each group, there was a positive correlation only in the control group between PSQI scores and the number of cigarettes smoked daily. The effect of daily cigarette smoking on poor sleep quality was approximately $67 \%$ in healthy controls.

The sleep pattern is known to vary with age, and insomnia increases with age. Our study also determined that sleep quality deteriorates with age. This result is consistent with the body of literature ${ }^{31}$.

High BMI may adversely affect many systems, from metabolic issues to the respiratory tract. Sleep quality worsens owing to such effects $^{32}$. In our study, as BMI increased, the sleep quality worsened.

The poorer sleep quality in those individuals with shorter disease duration may be due to experiencing more sleep disruption in the initial periods of the disease due to acute anxiety. The sleep disorder may improve if the patients develop mechanisms to cope with the problem in time.

Sleep disorder gives rise to significant losses of functionality in daily life. The significant sleep disorders associated with GAD are not fully healed. It has been demonstrated that individuals with anxiety disorders and poor sleep have significantly worse mental health-related quality of life and increased disability compared to those with anxiety disorders alone ${ }^{11}$. Although the symptoms of anxiety improve during the periods of wellness in the patients with $\mathrm{PD}$ and GAD, the other residual symptoms can persist. In PD and $\mathrm{GAD}$, disruption with respect to some areas of sleep, in addition to overall deterioration of sleep quality, is more common.

The fact that this study is cross-sectional, with a small number of participants, serves as a significant limitation. Although the PSQI is a validated sleep quality scale, it alone is not sufficient for the evaluation of sleep quality and the sub-components of sleep disorders. In larger sample groups, the quality of sleep should be evaluated by more objective tests, such as actigraphy or polysomnography, and follow-up studies should further be conducted. Caffeine intake may affect sleep quality. Participants weren't asked about their amounts of caffeine and black tea intake.

Consequently, the sleep disorder is an important component of anxiety disorders. Although treatments aimed at the primary disease may result in improved symptoms, this result itself is not sufficient. The sleep disorder in patients with GAD may persist despite adequate treatment of the anxiety symptoms. Enquiring about sleep disorder in patients with GAD in remission, and administering pharmacologically and non-pharmacologically specific treatments intended for this purpose, is of great importance.

\section{Disclosure}

No conflicts of interest are declared by the authors.

\section{Financial disclosure}

The authors declare that this study has received no financial support.

\section{References}

1. Kessler RC, Berglund P, Demler O, Jin R, Merikangas KR, Walters EE. Lifetime Prevalence and Age-of-Onset Distributions of DSM-IV Disorders in the National Comorbidity Survey Replication. Arch Gen Psychiatry. 2005;62(6):593-602.

2. Remes $\mathrm{O}$, Brayne $\mathrm{C}$, van der Linde R, Lafortune L. A systematic review of reviews on the prevalence of anxiety disorders in adult populations. Brain Behav. 2016;6(7):e00497.

3. Baxter AJ, Vos T, Scott KM, Ferrari AJ, Whiteford HA. The global burden of anxiety disorders in 2010. Psychol Med. 2014;44(11):2363-74.

4. Mellman TA. Sleep and anxiety disorders. Sleep Med Clin. 2008;3:261-8.

5. Kyle SD, Morgan K, Espie CA. Insomnia and health-related quality of life. Sleep Med Rev. 2010;14(1):69-82. 
6. Szentkirályi A, Madarász CZ, Novák M. Sleep disorders: impact on daytime functioning and quality of life. Expert Rev Pharmacoecon Outcomes Res. 2009;9(1):49-64.

7. Sateia MJ. Update on Sleep and Psychiatric Disorders. Chest. 2009;135(5):1370-9.

8. Papadimitriou GN, Linkowski P. Sleep disturbance in anxiety disorders. Int Rev Psychiatry. 2005;17(4):229-36.

9. Cinosi E, Di Iorio G, Acciavatti T, Cornelio M, Vellante F, De Risio L, et al. Sleep disturbances in eating disorders: a review. Clin Ter. 2011;162(6):e195-202.

10. Roth T, Jaeger S, Jin R, Kalsekar A, Stang PE, Kessler RC. Sleep Problems, Comorbid Mental Disorders, and Role Functioning in the National Comorbidity Survey Replication. Biol Psychiatry. 2006;60(12):1364-71.

11. Ramsawh HJ, Stein MB, Belik SL, Jacobi F, Sareen J. Relationship of anxiety disorders, sleep quality, and functional impairment in a community sample. J Psychiatr Res. 2009;43(10):926-33.

12. Cox RC, Olatunji BO. A systematic review of sleep disturbance in anxiety and related disorders. J Anxiety Disord. 2016;37:104-29.

13. Staner L. Sleep and anxiety disorders. Dialogues Clin Neurosci. 2003;5:249-58.

14. Ferre Navarrete F, Pérez Páramo M, Fermin Ordoño J, López Gómez V. Prevalence of Insomnia and Associated Factors in Outpatients With Generalized Anxiety Disorder Treated in Psychiatric Clinics. Behav Sleep Med. 2017;15(6):491-501.

15. American Psychiatric Association. Diagnostic and Statistical Manual of Mental Disorders, 5th ed. Washington, DC: American Psychiatric Association; 2013.

16. Hoge EA, Marques L, Wechsler RS, Lasky AK, Delong HR, Jacoby RJ, et al. The role of anxiety sensitivity in sleep disturbance in panic disorder. J Anxiety Disord. 2011;25:536-8.

17. Buysse DJ, Reynolds CF 3rd, Monk TH, Berman SR, Kupfer DJ. The Pittsburgh Sleep Quality Index: a new instrument for psychiatric practice and research. Psychiatry Res. 1989;28(2):193-213.

18. Ağargün MY, Kara H, Anlar Ö. The Validity and Reliability of the Pittsburgh Sleep Quality Index. Türk Psikiyatr Derg. 1996;7:107-15.

19. Beck AT, Ward CH, Mendelson M, Mock J, Erbaugh J. An inventory for measuring depression. Arch Gen Psychiatry. 1961;4:561-71.
20. Hisli N. Beck depresyon envanteri’nin geçerliği üzerine bir çalışma. Türk Psikol Derg. 1988;22:118-26.

21. Beck AT, Epstein N, Brown G, Steer RA. An inventory for measuring clinical anxiety: Psychometric properties. J Consult Clin Psychol. 1988;56(6):893-7.

22. Ulusoy M, Sahin NH, Erkmen H. Turkish Version of the Beck Anxiety Inventory: Psychometric Properties. J Cogn Psychother. 1998;12:163-72.

23. Öztürk AB, Özenli Y, Öztürk SB, Önel S, Söker G, Seydaoglu G. The effect of psychoeducation on anxiety and pain in patients with mastalgia. Nord J Psychiatry. 2015;69(5):380-5.

24. Roy-Byrne PP, Uhde TW, Post RM. Effects of one night's sleep deprivation on mood and behavior in panic disorder. Patients with panic disorder compared with depressed patients and normal controls. Arch Gen Psychiatry. 1986;43(9):895-9.

25. Alfano CA, Ginsburg GS, Kingery JN. Sleep-related problems among children and adolescents with anxiety disorders. J Am Acad Child Adolesc Psychiatry. 2007;46(2):224-32.

26. Harvey AG. A cognitive model of insomnia. Behav Res Ther. 2002;40(8):869-93.

27. Brenes GA, Miller ME, Stanley MA, Williamson JD, Knudson M, McCall WV. Insomnia in older adults with generalized anxiety disorder. Am J Geriatr Psychiatry. 2009;17(6):465-72.

28. Monti JM, Monti D. Sleep disturbance in generalized anxiety disorder and its treatment. Sleep Med Rev. 2000;4(3):263-76.

29. McNamara JPH, Wang J, Holiday DB, Warren JY, Paradoa M, Balkhi $\mathrm{AM}$, et al. Sleep disturbances associated with cigarette smoking. Psychol Health Med. 2014;19(4):410-9.

30. Cohrs S, Rodenbeck A, Riemann D, Szagun B, Jaehne A, Brinkmeyer J, et al. Impaired sleep quality and sleep duration in smokers-results from the German Multicenter Study on Nicotine Dependence. Addict Biol. 2014;19(3):486-96.

31. Atalay H. Comorbidity of insomnia detected by the Pittsburgh Sleep Quality Index with anxiety, depression and personality disorders. Isr J Psychiatry Relat Sci. 2011;48(1):54-9.

32. Vargas PA, Flores M, Robles E. Sleep Quality and Body Mass Index in College Students: The Role of Sleep Disturbances. J Am Coll Health. 2014;62(8):534-41. 